Sylvie Auxilien Henri Grosjean

\title{
Édition des ARN d'eucaryotes et viraux par désamination enzymatique d'adénosines en inosines
}

Par désamination de l'adénosine, des désaminases nucléaires spécifiques produisent des résidus inosine qui, incorporés dans des ARN messagers ou viraux, se conduisent comme des résidus guanosine dans les étapes ultérieures de transcription et de traduction, altérant ainsi l'information génétique codée par l'ADN : ce phénomène est appelé editing; il s'agit d'une édition au sens de «correction sur épreuve". L'inosine est présente dans l'anticodon de plusieurs ARN de transfert des cellules eucaryotes, mais aussi dans la région codante de certains ARN messagers (récepteur du glutamate dans le cerveau, transcrit non codant du VIH-1, régions double-brin d'ARNm eucaryote associé à des oligonucléotides antisens). Elle est aussi vraisemblablement présente dans les premiers transcrits de réplication de certains virus (virus de la rougeole et de l'hépatite delta). Les modalités de reconnaissance des différentes adénosine désaminases sont peut-être voisines de celles conduisant à la désamination de la cytosine (conversion $\mathrm{C} / \mathrm{U}$ ) observée dans l'ARNm de l'apolipoprotéine $B$ dans l'intestin.

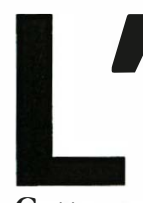

un des principes de base de la biologie moléculaire est la colinéarité du gène avec l'ARN messager et la protéine qui en résultent. Cette notion, issue principalement de travaux sur la génétique des systèmes bactériens, ne s'applique pas toujours lorsque l'on compare les gènes avec leurs produits de transcription et de traduction chez les organismes supérieurs. En effet, de nombreux gènes d'eucaryotes contiennent des séquences nucléotidiques non codantes (introns). Toutefois, étant donné que ces séquences introniques de gènes ainsi "morcelés " sont éliminées lors de la maturation post-transcriptionnelle de l'ARN, le principe de colinéarité entre les parties strictement exoniques des gènes et les séquences peptidiques correspondantes dans les protéines est respecté.

En revanche, dans un processus posttranscriptionnel du type "édition de 


\section{RÉFÉRENCES}

1. Benne R, Van Den Burg J, Brakenhoff IPI, Sloof P, Van Boom JH, Tromp MC. Major transcript of the frameshifted coxII gene from trypanosome mitochondria contains from trypanosome mitochondria contains the DNA. Cell 1986; 46: 819-26.

2. Benne $\mathrm{R}$ (editor). RNA editing: the alteration of protein coding sequences of RNA. Ellis Horwood series in molecular biology. Turner A. series editor, Ellis Harwood Limited, NJ, 1983 (196 pages).

3. Cattaneo R. Different types of mRNA editing. Annu Rev Genet 1991; 25 : 71-88.

4. Bonnard G, Gualberto JM, Lamattina L, Grienenberger IM. RNA editing in plant mitochondria. Crit Rev Plant Sai 1992; 10: 503-24.

5. Bass LB. RNA editing: new uses for old players in RNA world. In: Gesteland R, Atkins J, eds. The RNA World. Cold Spring Harbor Laboratory Press, 1993: 383-418.

6. Chan L. RNA editing: exploring one mode with apolipoprotein B mRNA. Biotssays $1993 ; 15: 33-41$

7. Powell LM, Wallis SC, Pease RI, Edwards YH, Knott TJ, Scott J. A novel form of tissuespecific RNA processing produces apoliprotein-B48 in intestine. Cell 1987; $50: 831-40$.

8. Chen SH, Habib G, Yang CY, Gu ZW, Lee BR, Weng SA, Silberman SR, Cai SJ, Deslypere JP, Rosseneu M, Gotto AM, Li WH, Chan L. Apolipoprotein B-48 is the product of a messenger RNA with an organ-specific in frame stop codon. Science 1987; 238: 363-6.

9. Navaratnam N, Patel D, Shah RR, Greeve JC, Powel LM, Knott Tj, Scott J. An additional editing site is present in apolipoprotein B mRNA. Nucleic Acids Res 1991 ; 19: 1741-4.

10. Hodges P, Scott J. Apolipoprotein B mRNA editing: a new tier for the control of gene expression Trends Biochem Sci 1992 17: 77-81

11. Beier H, Lee MC, Sekiya T, Kuchino Y, Nishimura S. Two nucleotides next to the anticodon of cytoplasmic rat tRNAasp are likely generated by RNA editing. Nucleic Acids Res 1992; 20 : 2679-83.

12. Sommer B, Köhler M, Sprengel R, Seeburg PH. RNA editing in brain controls a determinant of ion flow in glutamate-gated channels. Cell 1991; 67: 1119 .

13. Lomeli $\mathrm{H}$, Mosbacher J, Melcher T, Höger T, Geiger JRP, Kuner T, Monyer $\mathrm{H}, \mathrm{Hi}$ gushi M, Bach A, Seeburg PH. Control of kinetic properties of AMPA receptor channels by nuclear RNA editing. Science 1994; 266 : 1709-13.

14. Nutt SL, Kamboj RK. RNA editing of human kainate receptor subunits. Neuroreport $1994 ; 5: 2625-9$.

15. Bass LB, Weintraub H. A developmentally regulated activity that unwinds RNA duplexes. Cell 1987; 48: 607-13.

16. Rebagliati MR, Melton DA. Antisense RNA injections in fertilized frog eggs reveal an RNA duplex unwinding activity. Cell
l'ARN ", au sens de correction sur épreuve, la séquence des nucléotides de l'ARN messager édité et donc l'enchaînement des acides aminés dans la protéine correspondante, n'est plus conforme à la séquence en nucléotides du gène (morcelé ou non). Ce processus enzymatique d'un type nouveau est d'abord apparu sous la forme d'insertions d'uridines non codées par l'ADN dans un ARN messager de mitochondrie de trypanosome $\left(\mathrm{m} / \mathrm{s} n^{\circ} 7\right.$, vol. $8, p$. 764) [1]. Cette observation s'est rapidement étendue à toute une série d'autres ARN messagers (ARNm) mais également d'ARN de transfert (ARNt) issus de mitochondries de divers organismes eucaryotes (champignons, plantes supérieures, vertébrés) et de chloroplastes de plantes supérieures. Certains ARN de virus (les paramyxovirus de la rougeole et des oreillons ainsi que le virus de l'hépatite delta) n'ont pas échappé à la règle. Ce sont essentiellement des insertions et délétions d'uridines et de cytidines mais également des conversions de bases (cytosine en uracyle, uracyle en cytosine et adénine en hypoxanthine) qui ont été observées. La fréquence de ces phénomènes d'insertion-délétion de nucléotides ainsi que des conversions de bases dans certains ARN de ces organites d'organismes supérieurs ou de virus peut être si importante que la relation de colinéarité gène-ARNprotéine peut devenir méconnaissable après édition de l'ARN (pour revues, voir [2-6]).

\section{L'édition d'ARN dans le noyau de cellules eucaryotes}

Dans les ARN messagers et de transfert du cytosol de vertébrés, le changement de la séquence en nucléotides résultant de processus post-transcriptionnels du type édition reste, jusqu'à ce jour, un phénomène rare. Le cas le mieux connu est celui de l'édition de l'ARN messager de l'apolipoprotéine $B$, une protéine essentielle du plasma impliquée dans le transport des lipides $\left(\mathrm{m} / \mathrm{s} n^{\circ} 10\right.$, vol. 5, p.787). L'ARNm de cette protéine est modifié (édité) après transcription dans les cellules de l'intestin pour faire apparaître un codon d'arrêt UAA à la place d'un codon glutamine CAA, normalement codé dans le gène correspondant. Il en résulte une protéine plus courte (ApoB-48) avec 2152 acides aminés au lieu de 4536 (ApoB-100) à partir de l'ARN messager non édité présent dans d'autres cellules comme le foie $[7,8]$. Un deuxième site d'édition du type $\mathrm{C} / \mathrm{U}$ conduisant à la conversion d'un codon thréonine ACA en un codon isoleucine AUA a été identifié dans l'ARNm de l'apolipoprotéine B [9]. On a pu déterminer que la conversion de ces deux cytidines en uridines est catalysée par une cytidine désaminase présente dans le noyau de la cellule. Cette enzyme, de petite taille $(27 \mathrm{kDa})$, agit au sein d'un complexe multiprotéique (éditosome de $1400 \mathrm{kDa}$ ) dont l'activité est modulée par un ou plusieurs facteurs protéiques spécifiques de la cellule (tissu) considérée. Les signaux nécessaires, pour que le complexe d'édition reconnaisse la (ou les) cytidine(s) à modifier dans la région codante d'un ARN messager ne sont pas encore bien compris $\left(\mathrm{m} / \mathrm{s} n^{\circ} 10\right.$, vol. 9, p. 1129) (revue dans $[6,10]$ ). Un seul cas possible d'édition du type $\mathrm{C} / \mathrm{U}$ a été mentionné dans un ARN de transfert de cellules eucaryotes. Il concerne la conversion d'une séquence dinucléotidique $\mathrm{CU}$ en UC dans la boucle de l'anticodon de l'ARNt spécifique de l'acide aspartique du foie de rat [11]. Cette observation repose uniquement sur la base d'une comparaison de la séquence de l'ARNt cytoplasmique avec la séquence du gène correspondant. Aucune activité enzymatique n'a pu encore être détectée qui permettrait d'établir un lien ou une analogie quelconque avec d'autres cas d'édition du type $\mathrm{C} / \mathrm{U}$, par exemple dans l'ARNm de l'apolipoprotéine B ou dans les ARN de mitochondries et de chloroplastes.

Les autres cas d'édition post-transcriptionnelle rapportés à ce jour dans les ARN cytoplasmiques d'eucaryotes concernent des changements d'identité de codons dans des ARN messagers de sous-unités réceptrices du glutamate (GluR) faisant partie de canaux ioniques dans le cerveau des vertébrés $\left(\mathrm{m} / \mathrm{s} n^{\circ} 10\right.$, vol. 7, p. 1098) [12-14]. Ces changements d'identité de codons résultent de la conversion enzymatique d'adénosine en inosine, un nucléoside modifié 


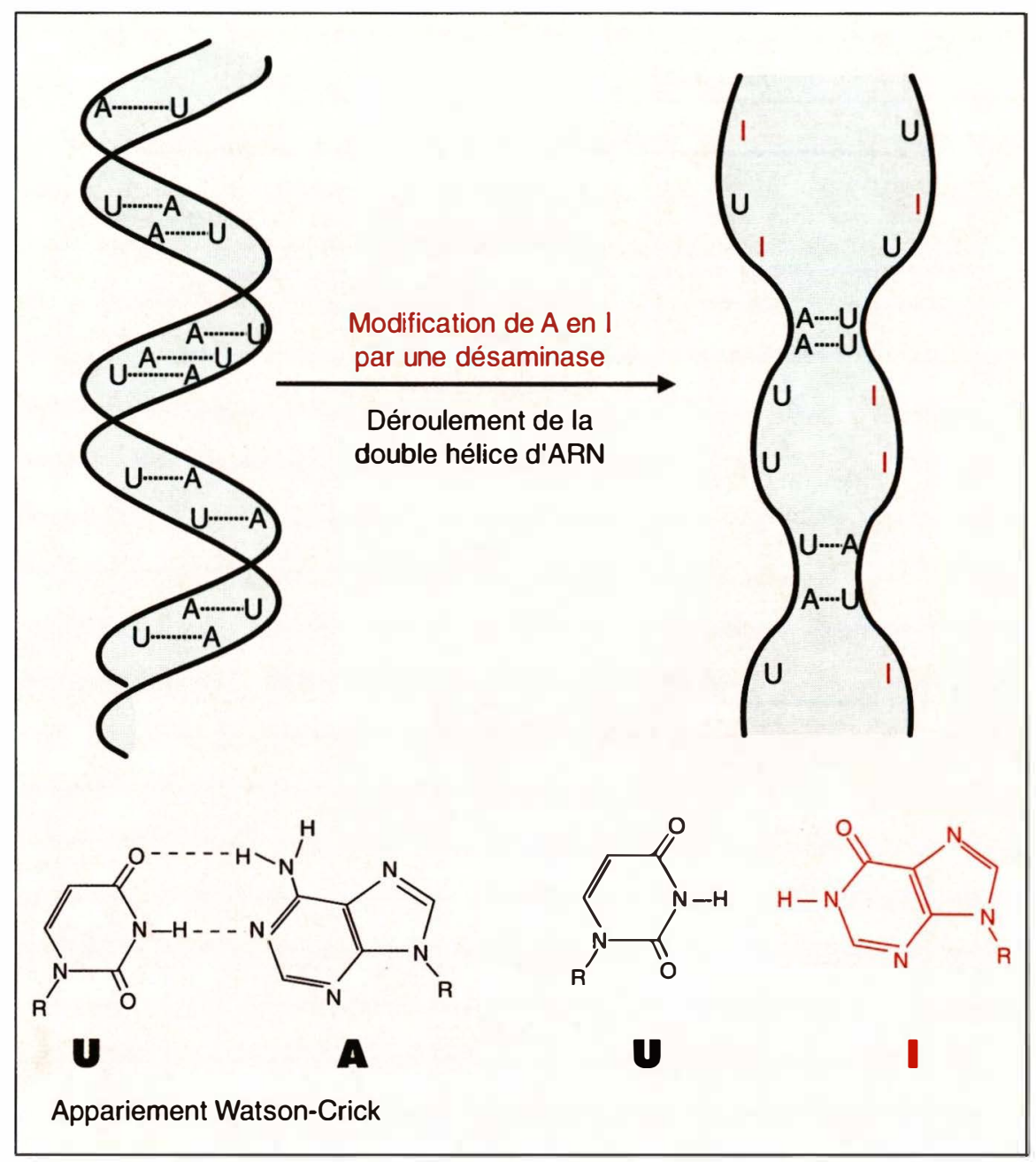

Figure 1. Représentation schématique de l'effet "déroulant" de l'adénosine désaminase d'ARN double-brin (dsRAD). Certaines adénosines de I'ARN double-brin sont désaminées en inosines, perdant ainsi leur capacité d'appariement type Watson-Crick avec les uridines. (Schéma adapté de [50]).

dont les propriétés codantes se rapprochent plus de celles de la guanosine que de l'adénosine dont elle dérive. La désamination enzymatique de l'adénosine en inosine dans des ARN polymères lors de leur maturation n'est certes pas un phénomène nouveau. En revanche, ce qui est remarquable, c'est le fait que l'apparition d'un nucléoside non canonique comme l'inosine dans la région codante d'ARNm soit à la base d'un mécanisme original de changement de l'information génétique. Nous faisons ici le point sur ce que l'on sait de la biosynthèse et des fonctions de l'inosine dans différents types d'ARN.
Cette activité enzymatique est d'abord apparue comme une "déroulase" d'ARN (RNA unwinding protein). Faible ou quasi inexistante aux stades précoces de l'ovogenèse, elle apparaît surtout après la fécondation des ovocytes pour atteindre une valeur élevée dans les embryons et les cellules différenciées [15]; sa localisation cellulaire est essentiellement nucléaire [17]. Par la suite, cette même activité enzymatique a été décelée dans tous les types de cellules animales testées, son importance variant au cours du développement cellulaire [18]. Très rapidement il s'est avéré que l'activité " déroulase" d'ARN correspondait, en fait, à une activité enzymatique de transformation chimique d'adénosines en inosines $[19,20]$, à la fois dans la région codante de l'ARNm et dans l'oligonucléotide ARN antisens, appliquée aux adénosines de la région bicaténaire de l'ARN (jusqu'à $50 \%$ ) [21]. Les inosines néoformées s'appariant très imparfaitement avec les uridines du brin d'ARN complémentaire, il en résulte une déstabilisation importante de la double hélice d'ARN et la séparation (déroulement) des deux brins. Ceux-ci, une fois dissociés, ne peuvent plus se réassocier $[19,20]$ (figure 1).

L'enzyme responsable de ce phénomène a été purifiée à partir de différentes sources de cellules, clonée et appelée maintenant dsRAD ou encore DRADA (double-strand RNA adenosine deaminase) [22-25]. Avec un poids moléculaire apparent d'environ $120 \mathrm{kDa}$, elle se fixe sélectivement sur des régions d'ARN en double hélice, et y modifie toute une série d'adénosines sans spécificité stricte pour une séquence particulière de l'ARN cible. Cependant, dans le cas de l'ARNm codant pour bFGF (basic fibroblast growth factor) hybridé à un ARN antisens, ou des ARN double-brin synthétiques, la dsRAD modifie de préférence des adénosines situées en aval d'autres adénosines ou d'uridines [26, 27], sans préférence évidente pour des nucléotides qui suivent l'adénosine à modifier. L'efficacité de la réaction enzymatique de formation d'inosine dépend beaucoup de la longueur de l'ARN en doublebrin : 15 paires de bases parfaitement appariées représentent la longueur minimale requise, et la réaction n'est vraiment efficace que pour des ARN 


\section{RÉFÉRENCES}

17. Saccomanno L, Bass BL. The cytoplasm of Xenopus oocytes contains a factor that protects double-stranded RNA from adenosine-to-inosine modification. Mol Cell Biol $1994 ; 14: 5425-32$.

18. Wagner RW, Nishikura K Cell cycle expression of RNA duplex unwindase activity in mammalian cells. Mol Cell Biol 1988; 8: 770-7.

19. Bass BL, Weintraub $H$. An unwinding activity that covalently modifies its doublestranded RNA substrate. Cell 1988; 55: 1089-98.

20. Wagner RW, Smith JE, Cooperman BS, Nishikura K. A double-stranded RNA unwinding activity introduces structural alteration by means of adenosine to inosine conversions in mammalian cells and Xenopus eggs. Proc Natl Acad Sci USA 1989; 86 . pus eggs.

21. Nishikura K, Yoo C, Kim U, Murray JM, Estes PA, Liebhaber SA. Substrate specificity of dsRNA unwinding/modifying activity. EMBO J $1991 ; 10: 3523-32$.

22. Hough RF, Bass BL. Purification of the Xenopus qaevis double-stranded RNA adenosine deaminase. J Biol Chem 1994; 269: 9933-9.

23. Kim U, Garner TL, Sanford T, Speicher D, Murray JM, Nishikura K. Purification and characterization of double-stranded RNA adenosine deaminase from bovine nuclear extracts. J Biol Chem 1994; 269 : 13480-9.

24. O'Connell MA, Keller W. Purification and properties of double-stranded RNA-specific adenosine deaminase from calf thymus. Proc Natl Acad Sci USA 1994; 91 : 10596-600.

25. Kim U, Wang Y, Sanford T, Zeng Y, Nishikura K. Molecular cloning of cDNA for double-stranded RNA adenosine deaminase, a candidate enzyme for nuclear RNA editing. Proc Natl Acad Sci USA 1994; 91 : 11457-61.

26. Kimelman DC, Kirschner MW. An antisense mRNA directs the covalent modification of the transcript encoding fibroblast growth factor in Xenopus oocytes. Cell 1989 ; 59: 687-96.

27. Polson AG, Bass BL. Preferential selection of adenosines for modification by double-stranded RNA adenosine deaminase. $E M B O J 1994$; 13 : $5701-11$.

28. Scharmeen L, Bass BL, Sonenberg N, Weintraub H, Groudine M. Tat-dependen adenosine-to-inosine modification of wildtype transactivation response RNA. Proc Natl Acad Sci USA 1991 ; 88: 8096-100.

29. Rataul SM, Hirano A, Wong TC. Irreversible modification of measles virus RNA in vitro by nuclear RNA-unwinding activity in human neuroblastoma cells. I Virol 1992 $66: 1769-73$.

30. Bass BL, Weintraub H, Cattaneo R, Billeter MA. Biased hypermutation of viral RNA genomes could be due to unwinding / modification of double-stranded RNA. Cell 1989;

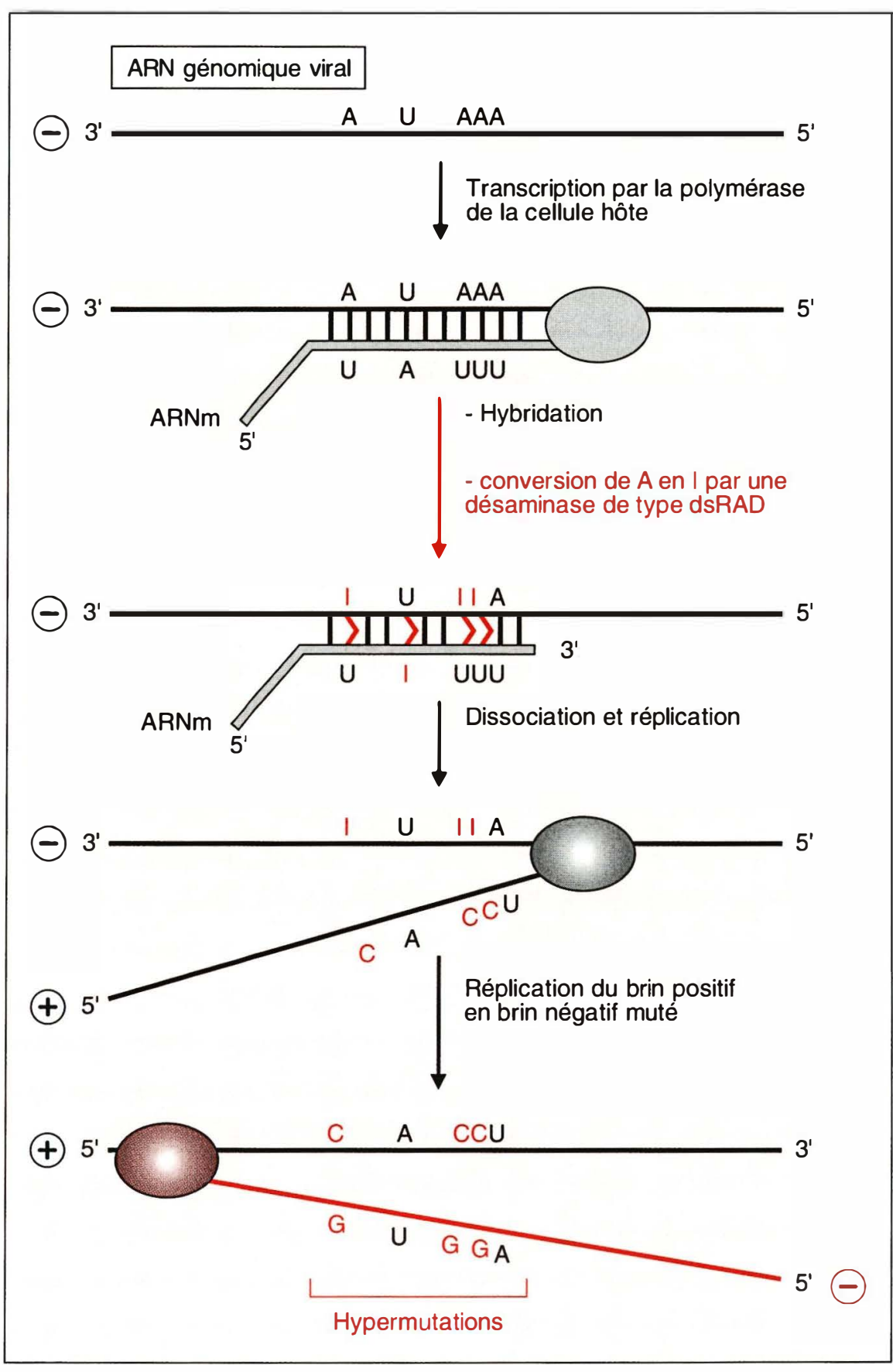

Figure 2. Schéma hypothétique de mutation $A$ en $G$ dans les $A R N$ viraux par une désaminase de type dsRAD. Les protéines se fixant sur l'ARN simple brin et qui empêchent l'ARNm de s'hybrider à l'ARN génomique viral n'ont pas été représentées. Dans ce modèle, les conversions d'adénosines en inosines se passent au niveau de l'hybride formé entre l'ARN messager et I'ARN génomique viral lors de la première transcription catalysée par la polymérase de la cellule hôte. (Schéma adapté de [30]). 
bicaténaires dont la longueur est au moins égale à 100 paires de bases [21]. Les parties en double hélice peuvent être du type intermoléculaire, comme celles formées entre deux fibres complémentaires d'ARN (un $\mathrm{ARNm}$ et un oligonucléotide antisens, par exemple) ou du type intramoléculaire, comme celles formées par de longues tiges-boucles d'ARN repliés sur eux-mêmes.

\section{Le cas des ARN viraux}

Une inosine a été détectée au niveau de la séquence TAR (transactivation response) à l'extrémité 5 ' non codante des ARN transcrits du gène du virus de l'immunodéficience humain de type 1 (VIH-1) après microinjection dans le noyau d'ovocytes de $X$. laevis [28]. Cette séquence TAR a une structure en épingle à cheveux dont la tige comporte 23 paires de bases appariées. L'interaction de cette séquence TAR avec la protéine virale Tat permet le contrôle de l'expression du VIH-1 au niveau de sa transcription et de sa traduction par un mécanisme encore inconnu. La modification enzymatique d'une seule adénosine en inosine dans cette séquence TAR semble être responsable de l'activation de la traduction des transcrits de VIH-1. Toutefois, cette transformation chimique (édition d'ARN) ne peut se produire que si la protéine Tat est présente [28].

Dans le cas d'autres virus à ARN, par exemple les virus de la rougeole (measles viruses, MV) de la famille des Paramyxovirus, dont la persistance engendre des encéphalites létales, on évoque également la transformation d'adénosines en inosines dans l'ARN du virus lors de sa première réplication dans la cellule hôte par une enzyme du type dsRAD [29, 30]. Toutefois, l'identification d'inosines dans l'ARN au cours du cycle primaire de réplication du virus n'a pas encore été réalisée. En effet, l'inosine ayant des propriétés d'appariement identiques à celles de la guanosine, elle ne peut pas être distinguée de cette dernière lors de la détermination des séquences nucléotidiques réalisées à partir des ADN complémentaires (ADNc). La formation enzymatique de telles inosines dans ce type de virus expliquerait toutefois les fréquences de mutations relativement élevées du type U (s'appariant normalement avec A) en C (s'appariant maintenant avec I ou $G$ ) (figure 2), notamment dans les gènes de protéines d'enveloppe et de protéines de réplication [31].

\section{Le cas des ARN de transfert}

L'inosine est un nucléoside trouvé pour la première fois dès les années 1960 dans l'anticodon de toute une série d'ARN de transfert (ARNt). Dans tous les organismes eucaryotes, cette inosine est présente à la première position de l'anticodon (position 34) des ARNt spécifiques de la leucine, l'isoleucine, la valine, la sérine, la proline, la thréonine, l'alanine et l'arginine. Dans l'ARNt spécifique de l'alanine, on trouve également une inosine méthylée ( $\mathrm{m}^{1}$-inosine) en position-37, adjacente à l'anticodon (figure 3) [32]. Ces inosines résultent de modifications post-transcriptionnelles de l'adénosine en positions 34 et/ou 37, catalysées chacune par une désaminase spécifique du site de modification dans l'ARNt (position 34 ou 37) et parfaitement séparables l'une de l'autre par chromatographie au cours des étapes de purification ([33], Auxilien et Simon, résultats non publiés). Elles agissent exclusivement au niveau d'adénosines de la boucle anticodon d'ARNt et n'agissent absolument pas sur des fragments d'ARNt ni même sur des ARNt mutés dans l'une ou l'autre de leurs liaisons tertiaires caractéristiques (Auxilien, résultats non publiés). Les activités des enzymes catalysant la formation d'inosines dans les boucles d'anticodon des ARNt sont donc extrêmement dépendantes de la structure tridimensionnelle intacte des ARNt, très différente d'un ARN en double-brin. Ce sont donc nécessairement des enzymes distinctes qui catalysent la formation d'inosines dans ces deux types d'ARN polymères. Une inosine méthylée du type $\left(\mathrm{m}^{1}\right.$ inosine) a également été identifiée à la position 57, dans l'une des boucles de plusieurs ARNt de cellules halophiles et hyperthermophiles (archaebactéries) [34] (figure 3). A ce jour, on connaît peu de chose concernant le mécanisme et la spécificité de l'enzyme (ou du système enzymatique) qui catalyse la formation de ce nucléoside modifié [35].

\section{Le cas des ARN messagers}

La présence d'une inosine dans la région codante d'un ARN messager a été initialement soupçonnée dans l'ARNm d'une sous-unité de canaux ioniques du cerveau, le récepteur GluR-B dépendant du glutamate chez la souris [12]. Cette hypothèse a été très rapidement confirmée et étendue à toute une série d'autres ARNm de type GluR du cerveau de plusieurs vertébrés, y compris l'homme $[13,14$, 36]. La preuve formelle de la présence de l'inosine dans la région codante de ces $A R N m$ n'a cependant été apportée que très récemment [3739]. Les changements d'identité de codon observés à ce jour sont les suivants (I codant pour G): CAGG (glutamine) en CIG (arginine), $\underline{A} G A$ (arginine) en IGA (glycine), $\underline{A} U U$ (isoleucine) en IUU (valine), UAC (tyrosine) en UIC (cystéine).

L'activité enzymatique d'édition responsable de la formation des inosines dans les ARN messagers GluR est nécessairement localisée dans le noyau de la cellule puisqu'elle agit lors de la maturation du précurseur d'ARN messager, avant l'épissage des introns par le spliceosome [13, 40, 41]. Ces introns contiennent des séquences complémentaires permettant de former des appariements intra-moléculaires entre l'extrémité 3' de l'exon (en amont) et l'intron immédiatement adjacent (en aval). La figure 4 illustre l'exemple du site d'édition A/I dans l'ARNm correspondant au site glutamine/arginine (Q/R) dans la sous-unité GluR-B (également appelée GluR-2) du récepteur AMPA (acide $\alpha$-amino-3-hydroxy-5-methylisoxazole-4-propionique) du cerveau de la souris. Toute mutation qui modifie la séquence de la région bicaténaire de l'ARN à proximité du site d'édition, préservant l'appariement type Watson-Crick, n'affecte en rien l'efficacité de la réaction d'édition A/I. En revanche, toute mutation qui déstabilise cette portion en doublebrin réduit fortement, ou abolit même, l'efficacité de la réaction d'édition, tant in vitro qu'in vivo [37, 40, 41]. Ces mêmes conclusions s'appliquent à l'édition $\mathrm{A} / \mathrm{I}$ au site arginine/glycine $(R / G)$ de la même sousunité GluR-B [13]. Ces observations avaient conduit à l'idée que l'édition 


\section{RÉFÉRENCES}

31. Cattaneo R, Billeter MA. Mutations and A/I hypermutations in measles virus persistent infections. Curr Top Microbiol Immunol $1992 ; 176: 63-74$

32. Limbach PA, Crain PF, McCloskey JA. The modified nucleosides of RNA: summary. Nucleic Acids Res 1994; 22: 2183-96.

33. Auxilien S, Trewyn $\mathbf{R}$, Grosjean $\mathrm{H}$. L'inosine-34 des ARNt se forme par une transformation chimique, probablement une désamination hydrolytique, de l'adénine 34. Arch Int Physiol Biochim Biophys 1993; 101 : B2.

34. Edmonds CG, Crain PF, Gupta R, Hashizume $\mathrm{T}$, Hocart CH, Kowalak JA, Pomerantz SC, Stetter KO, McCloskey IA. Posttranscriptional modification of tRNA in thermophilic Archae (Archaebacteria). I Bacteriol 1991 ; 173 : 3138-48.

35. Grosjean H, Foiret D, Daniels C. The biosynthesis of 1-methyl-inosine in tRNAs from halophilic archaebacteria differs from that in eukaryotic tRNAs. Arch Int Physiol Biochim Biophys 1994; 10: B77.

36. Rueter SM., Burns CM., Coode SA Mookherjee P, Emeson RB. Glutamate receptor RNA editing in vitro by enzymatic conversion of adenosine to inosine. Science $1995 ; 267: 1491-4$

37. Melcher T., Maas S., Higuchi M., Keller W., Seeburg PH. Editing of $\alpha$-amino-3-hydroxy-5-methylisoxazole-4-propionic acid receptor GluR-B pre-mRNA in vitro reveals site-selective adenosine to inosine conver sion. J. Biol Chem 1995; 270: 8566-70.

38. Cha JHJ, Kinsman SL, Johnston MV. RNA editing of a human glutamate receptor subunit. Mol Brain Res 1994; 22: 323-8.

39. Yang JH, Sklar P, Axel R, Maniatis T. Editing of glutamate receptor subunit $B$ pre-mRNA in vitro by site-specific deamination of adenosine. Nature $1995 ; 374: 77-81$.

40. Higuchi M, Single FN, Kohler M, Sommer B, Sprengel R, Seeburg PH. RNA editing of AMPA receptor subunit GluR-B: a base-paired intron-exon structure determines position and efficiency. Cell 1993; 75 . 1361-70.

41. Egebjerg J, Kukekov V, Heinmann SF. Intron sequence directs RNA editing of the glutamate receptor subunit GluR-2 coding sequence. Proc Nall Acad Sci USA 1994; 91 : $10270-4$.

42. Paschen W, Dux E, Djuricic B. Developmental changes in the extent of RNA editing of glutamate receptor subunit GluR-5 in rat brain. Neurosci Lett 1994; 174: 109-12.

43. Bernard A, Khrestchatisky M. Assessing the extent of RNA editing in the TmII regions of GluR-5 and GluR-6 kainate receptors during rat brain development. I Neurochem $1994 ; 62$ : 2057-60.

44. Paschen W, Djuricic B. Extent of RNA editing of glutamate receptor subunit GluR5 in different brain regions of the rat. Cell

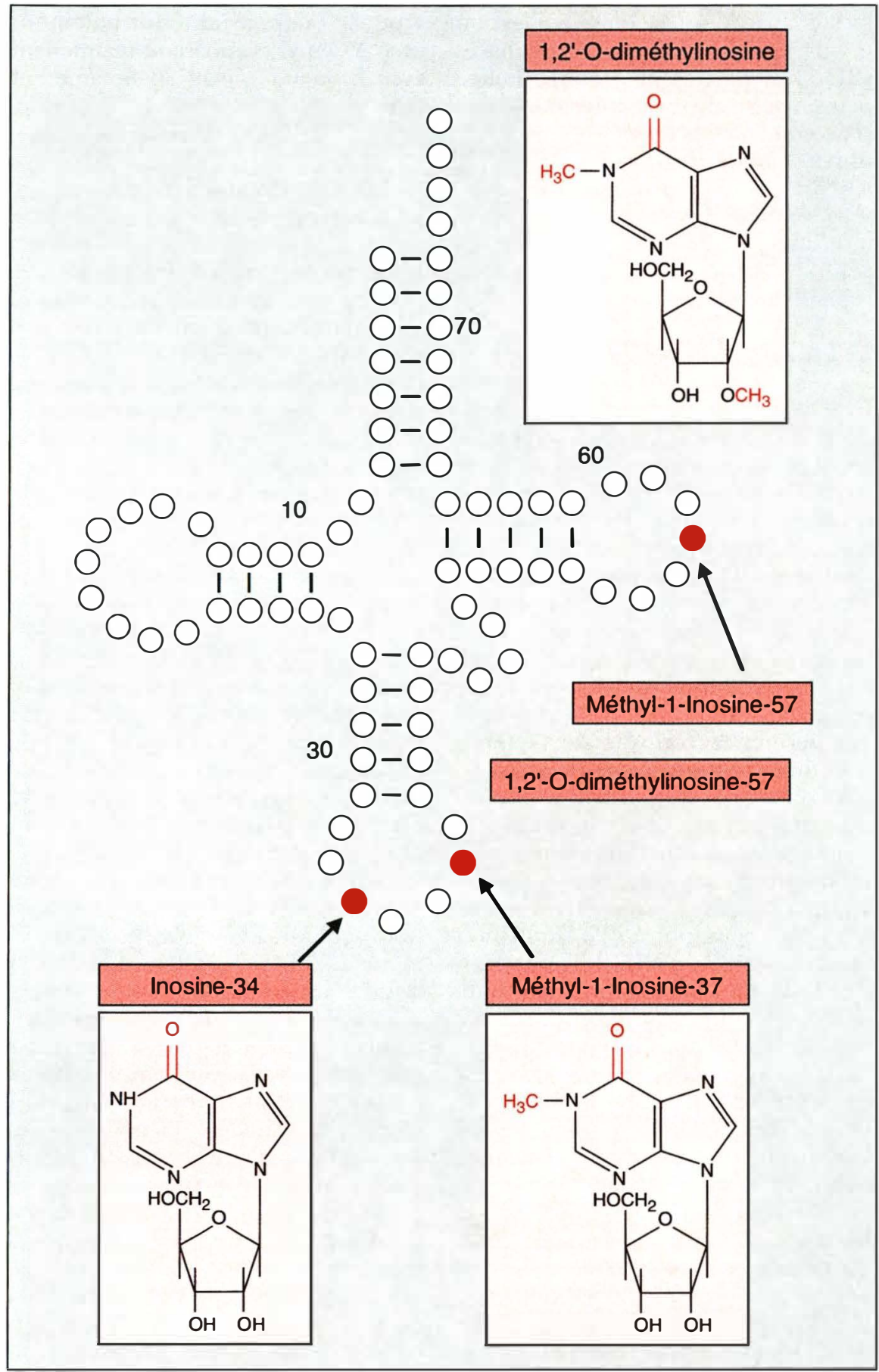

Figure 3. Structure schématique en feuille de trèfle d'un ARNt. Les différentes formes $d$ 'inosines que l'on peut $y$ trouver sont indiquées. Les positions 34 et 37 sont localisées dans la boucle anticodon. La position 57 se situe au milieu de la boucle "T" de l'ARNt. 


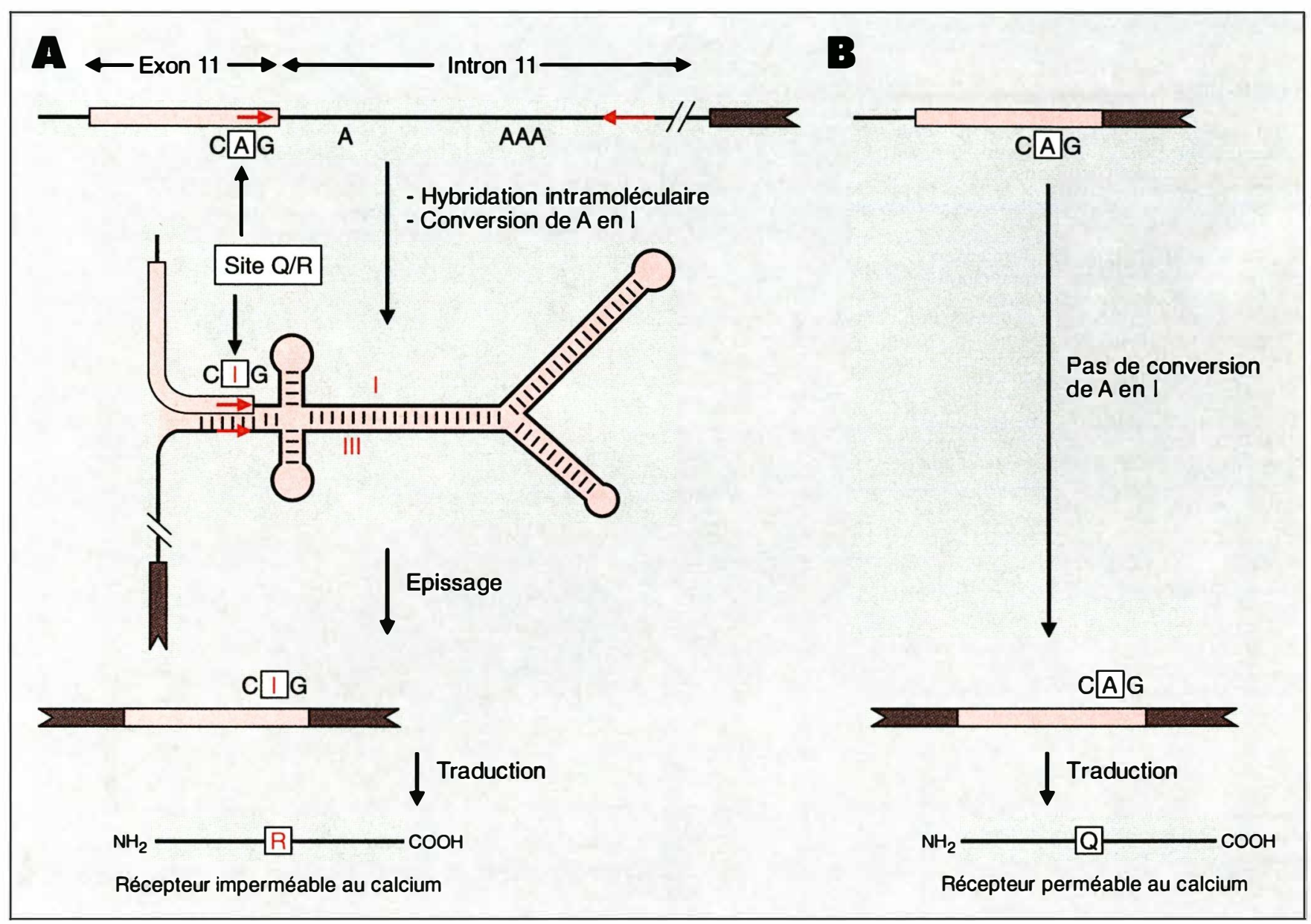

Figure 4. Réaction d'édition dans le préARNm de la sous-unité GluR-B (ou GluR-2) d'un récepteur du cerveau de souris dépendant du glutamate (récepteur AMPA). A. Avant épissage, l'exon 11 et l'intron 11 du préARNm de GluR-B sont appariés formant un ARN double-brin intramoléculaire. Cinq adénosines de cet ARN bicaténaire sont modifiées en inosine. L'inosine appartenant à l'exon (encadrée dans le schéma) induit alors un changement de codon (CAG en CIG) qui se traduit au niveau de la protéine par le changement d'une glutamine en arginine à un site appelé $Q / R$. Ce changement $d^{\prime}$ acide aminé a pour effet de rendre le récepteur imperméable au calcium [11, 49-51]. B. Si on effectue une délétion de l'intron 11 dans le préARNm, la réaction de modification de l'adénosine en inosine au site $Q / R$ ne peut plus avoir lieu. Ce résultat expérimental montre que l'étape d'hybridation intramoléculaire du préARNm sous forme double-brin est déterminante pour la réaction de modification [111. (Schéma adapté de [37] et [47].)

$\mathrm{A} / \mathrm{I}$ aux sites $\mathrm{Q} / \mathrm{R}$ et $\mathrm{R} / \mathrm{G}$ des ARNm de sous-unités de récepteurs de cerveau pourrait être due à la dsRAD (ou DRADA) agissant sur les ARN bicaténaires, ou du moins à une enzyme du même type. Toutefois, des résultats récents obtenus dans des systèmes acellulaires in vitro démontrent l'existence d'une activité enzymatique d'édition de l'ARN messager de la sous-unité GluR-B du type adénosine désaminase qui est distincte de celle qui catalyse la formation d'inosines dans les double-brins d'ARN [37]. Cette nouvelle enzyme pourrait être, comme dans le cas des adénosines désaminases agissant en position 34 ou 37 des ARN de transfert, très spécifique du site et de l'ARN messager à éditer. Alternativement, comme dans le cas de l'édition de l'ARNm de l'apolipoprotéine B, la sélection du site d'édition au sein de l'ARN messager pourrait se faire au niveau d'un complexe multienzymatique (éditosome) dont les composants, probablement des protéines ayant des affinités particulières pour des double-brins d'ARN, sont encore à identifier. Les bases moléculaires de ce système d'édition de l'ARNm et les conditions qui déterminent l'expression et/ou la régulation de l'activité enzymatique correspondante dans différentes régions du cerveau ainsi qu'à différents stades de développement de l'animal, restent cependant encore mal connues [42-45].

\section{Mécanisme de la formation d'inosine}

Le mécanisme des enzymes qui catalysent la formation de l'inosine tant au niveau des polymères $\mathrm{ARNm}$, des 


\section{RÉFÉRENCES}

45. Paschen W, Djuricic B. Regional differences in the extent of RNA editing of the glutamate receptor subunits GluR-2 and GluR-6 in rat brain. J Neurosci Methods 1995; $56: 21-9$.

46. Polson AG, Crain PF, Pomerantz SC, McCloskey JA, Bass BL. The mechanism of adenosine to inosine conversion by the double-stranded RNA unwinding/modifying activity: a high-performance liquid chromatography-mass spectrometry analysis. Biochemistry 1991; 30: 11507-14.

47. Wilson DK, Rudolph FB, Quiocho FA. Atomic structure of adenosine deaminase complexed with a transition-state analog: understanding catalysis and immunodefciency mutations. Srience 1991; 252: 127884.

48. Merkler DJ, Kline PC, Weiss P, Schramm VL. Transition-state analysis of AMP deaminase. Biochemisiry 1993; 32: 12993-3001.

49. Frick L, Wolfenden R, Smal E, Baker DC. Transition-state stabilization by adenosine deaminase: structural studies of its inhibitory complex with deoxycoformycin. Biochemistry 1986; 25: 1616-21.

50. Nishikura K. Modulation of doublestranded RNAs in vivo by RNA duplex unwindase. In: Basergsa R, Denhardt DT, eds. Antisense Strategies. New York: The New York Academy of Sciences. Ann Acad Sci 1992; 660) : 240-50.

51. Egebjerg J, Heinemann SF. ( $a^{2+}$ permeability of unedited and edited versions of the kainate selective glutamate receptor GluR6. Proc Nall Acad Sri USA 1993; 90 : 7559.

52. Kölher M, Burnashev N, Sakmann B, Seeburg PH. Determinants of $\mathrm{Ca}^{2+}$ permeability in both TM1 and TM2 of high affinity kainate receptor channels : diversity by RNA editing. Neuron 1993; 10: 491-500.

53. Köhler M, Kornau H-C, Seeburg PH. The organization of the gene for the func tionally dominant $\alpha$-amino-3-hydroxy-5-methyl-isoxazole-4-propionic acid receptor subunit GluR-B. J Biol Chem 1994; 269: 17367-70.

54. Boren T, Elias P, Samuelsson T, Claesson C, Barciszewska M, Gehrke CW, Kuo KC, Lustig F. Undiscriminating codon reading with adenosine in the wobble position. J Mol Biol 1993; 230: 739-49.

55. Munz P, Leupold U, Agris P, Kohli J. In vivo decoding rules in Schizosaccharomyres pombe are at variance with in vitro data. $\mathrm{Na}$ ture 1981 ; 294 : 187-8.

56. Hagervall TG, Tuohy TMF, Atkins JF, Björk GR. Deficiency of 1-methylguanosine in transfer RNA from Salmonella typhimurium induces frameshifting by quadruplet translocation. J Mol Biol 1993; 232: 756-5.

57. Cattaneo R. RNA duplexes guide base

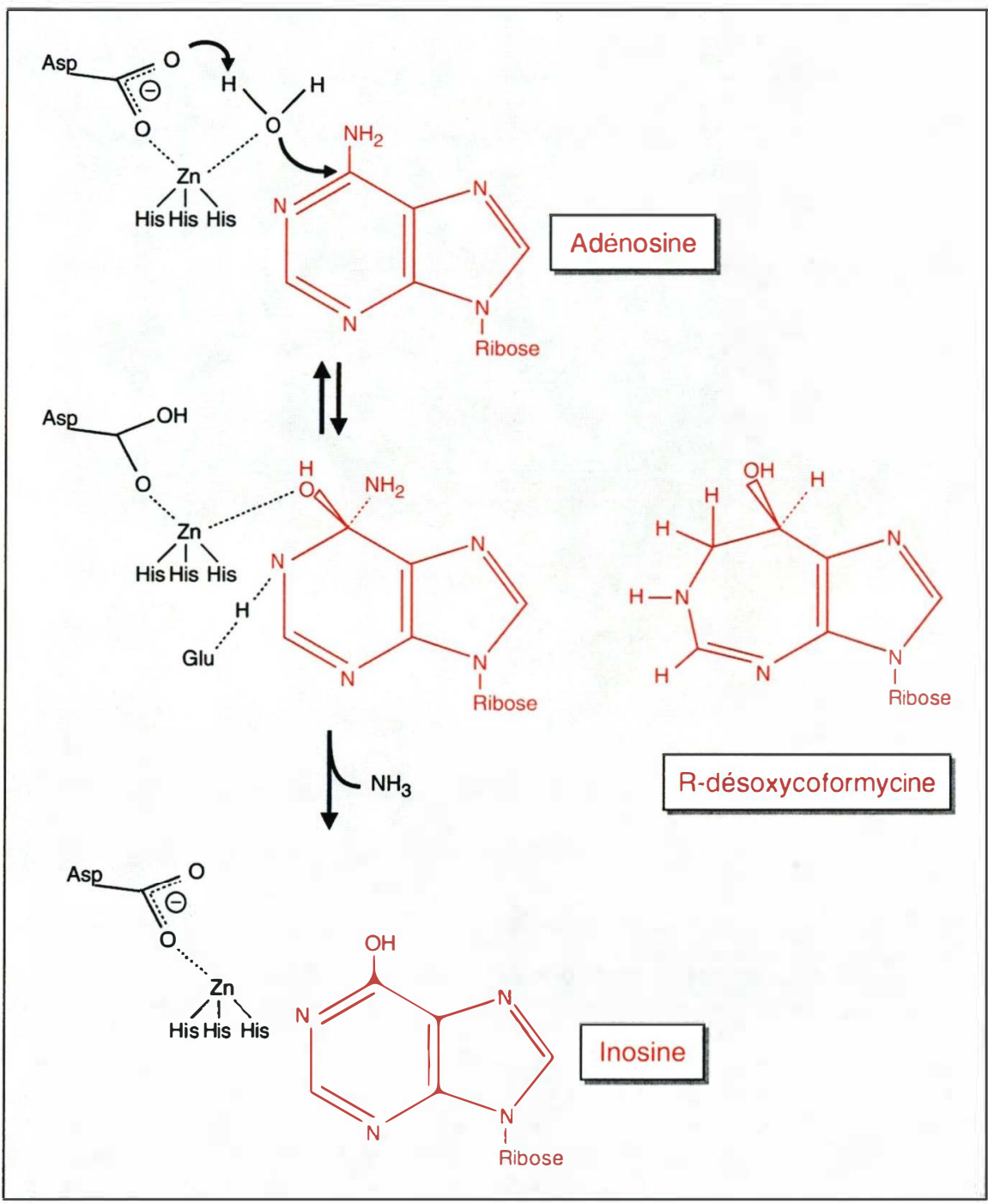

Figure 5. Mécanisme schématique de l'adénosine désaminase (ADA) catalysant la formation d'inosine par désamination hydrolytique de l'adénosine facilitée par un ion zinc. Dans le site actif de l'ADA, l'attaque de l'eau sur le carbone 6 est facilitée par une catalyse générale basique grâce à un résidu aspartate du site actif et une catalyse électrophile par un ion $\mathrm{Zn}^{2+}$ pentacoordiné avec l'eau, le résidu aspartate évoqué précédemment et 3 résidus histidines. Cette réaction conduit à la formation d'un intermédiaire tétraédrique de type sp3. Un résidu glutamique (Glu) protoné pourrait donner ou partager un proton avec N-1 du substrat. Le groupement amine de l'intermédiaire est ensuite éliminé pour former l'inosine. La R-désoxycoformycine, également représentée, est un inhibiteur compétitif très efficace de l'ADA (Ki = 2,5 pM). II correspond à un analogue structural de l'état de transition de la réaction. (Schéma adapté de [31]).

ARN double-brin et des ARNt est du type désaminase $[37,46]$ (Auxilien, résultats non publiés). Il est analogue ou identique au mécanisme bien connu de l'adénosine désaminase (ADA) agissant sur le nucléoside [47] ou de l'AMP désaminase agissant sur le nucléotide monomère [48] au cours des étapes du catabolisme des purines. Des études cristallogra- phiques détaillées de l'ADA ont permis de démontrer que l'inosine est formée par l'addition du groupe hydroxyl de l'eau sur le carbone 6 de l'adénine, suivie de l'élimination de l'ammoniaque (figure 5). Un analogue de l'intermédiaire de transition de la réaction enzymatique, la R-désoxycoformycine inhibe très fortement cette réaction: la constante d'inhibition 
compétitive est l'une des plus élevées que l'on ait pu mesurer pour une réaction enzymatique $\left(\mathrm{Ki}=2,5.10^{-12} \mathrm{M}\right)$ [49]. Cette R-désoxycoformycine n'inhibe absolument pas les enzymes qui catalysent la formation d'inosines dans les ARN polymères (ARN double-brin, messagers ou de transfert) ([46], Auxilien, résultats non publiés). Cette absence d'inhibition ne signifie pas que le mécanisme des enzymes agissant sur les ARN polymères puisse être différent de celui des enzymes qui agissent sur le nucléoside ou le nucléotide monophosphate dérivé de l'adénine, mais plutôt que le type d'interaction entre le substrat type polymère et l'enzyme correspondante ne permet pas la liaison avec l'inhibiteur type monomère coformycine. De plus, l'adénosine désaminase (ADA), de même que l'AMP-désaminase, impliquées dans le métabolisme des purines, n'agissent absolument pas sur les ARN double-brin ou les ARNt [46]. Inversement les ARN désaminases ne catalysent pas la formation d'inosine à partir du nucléoside libre ou d'AMP. Les enzymes qui catalysent la formation d'inosine dans les différents types d'acides nucléiques (monomères et polymères) sont parfaitement distinctes et forment donc une nouvelle famille d'enzymes.

\section{Fonctions de l'inosine dans les ARN}

Dans le cas des ARN double-brin relativement longs (supérieurs à 2050 paires de bases appariées), la transformation enzymatique de plusieurs adénosines en inosines, catalysée par la dsRAD ou DRADA et observée dans les cellules eucaryotes, conduit à une déstabilisation de l'hybride ARN. Cette activité pourrait donc être impliquée dans la dégradation sélective d'ARN bicaténaires en favorisant une forme monocaténaire plus facilement hydrolysable par des ribonucléases cellulaires. Pour déstabiliser de telles molécules ARN:ARN, plusieurs adénosines doivent nécessairement être modifiées. La "déroulase" d'ARN (dsRAD) ferait dès lors partie d'un système de défense de la cellule contre des ARN double-brin viraux qui seraient ainsi sélectivement dégradés par des ribonucléases endogènes de la cellule hôte [50].
Dans le cas des ARN messagers et viraux, l'apparition post-transcriptionnelle de une ou plusieurs inosines en des sites d'édition privilégiés d'ARNm à durée de vie limitée, catalysée par une (ou plusieurs) enzyme(s) du type adénosine désaminase, permet d'introduire rapidement des variations fonctionnelles, non permanentes, dans la population de certaines protéines en fonction des besoins physiologiques de la cellule. Dans le cas des récepteurs glutamatergiques, la conversion de certains A en I permet le changement de leurs propriétés ioniques au cours du développement du système nerveux central [42, 43, 51]. Dans le cas particulier des sous-unités GluR-B des récepteurs du type AMPA, l'apparition d'une arginine à la place d'une glutamine au site d'édition rend le récepteur pratiquement imperméable au calcium [52, 53]. Dans le cas des sous-unités GluR-B, GluR-C et GluR-D des récepteurs cérébraux, l'apparition d'une glycine à la place d'une arginine au site d'édition modifie la vitesse de désensibilisation et de récupération à l'action du glutamate [13]. L'édition du type A/I dans les ARNm constitue donc un "réglage fin" de l'expression génétique au niveau post-transcriptionnel.

Dans le cas des ARNt, l'inosine-34 est essentielle pour un décodage correct de l'information génétique. En effet, une adénosine non modifiée en inosine à la première position de l'anticodon (position 34) est capable d'interagir indifféremment avec les quatre types de nucléotides $\mathrm{A}, \mathrm{G}, \mathrm{C}$ et U de la troisième position d'un codon [54]. La sélectivité de l'ARNt pour décoder efficacement les codons se terminant par $\mathrm{U}$ et $\mathrm{C}$, et dans une moindre mesure les codons se terminant par A, n'est possible qu'après formation enzymatique d'inosine-34 [55]. La raison d'être de la méthyl-1-inosine-37, adjacente au codon IGC de l'ARNt-ala des cellules eucaryotes, est moins évidente. Par analogie avec la fonction de méthyl-1guanosine-37 trouvée dans d'autres ARNt [56], on peut penser que la présence de méthyl-1-inosine-37 dans l'ARNt-ala servirait à réduire notamment les risques d'erreur de déphasage de l'ARNm lors de la traduction génétique (synthèse de polypeptides anormaux par exemple).

\section{Conclusions}

La présence d'inosine dans les ARN de transfert était connue depuis longtemps. Plusieurs travaux récents mentionnent maintenant la présence de l'inosine dans d'autres types d'ARN: ARN double-brin, ARN messagers et viraux. Jusqu'à présent, ces inosines étaient passées inaperçues parce qu'elles se comportent comme des guanosines lors des processus de la transcription et de la traduction génétique. Ce n'est que lorsque l'on compare la séquence du gène de l'ARN étudié à celle de l'ARNc du produit de transcription de ce gène que l'on peut rendre compte de l'existence d'un tel processus d'édition par modification chimique (enzymatique) de nucléotide. Ces inosines sont, en principe, identifiables par les techniques de séquençage direct de l'ARN modifié (édité). Toutefois, l'opération est difficile, voire même impossible, lorsqu'il s'agit de détecter une seule inosine parmi un grand nombre de nucléosides de l'ARN. C'est la raison pour laquelle ce type de transformation enzymatique d'adénosines en inosines dans les ARN messagers ou viraux a longtemps échappé à la vigilance des expérimentateurs. On peut parier que dans un avenir proche d'autres exemples d'édition par conversion de base du type adénosine en inosine ou cytidine en uridine que ceux rapportés plus haut seront révélés dans d'autres ARN cytoplasmiques de cellules eucaryotes.

L'enzyme qui catalyse la formation de l'inosine en position 34 dans l'anticodon des ARN de transfert est distincte de celle qui catalyse la formation de l'inosine en position 37, qui sont elles-mêmes distinctes de celles qui catalysent la formation de l'inosine dans d'autres types d'ARN (messagers et double-brin). L'activité enzymatique responsable de l'édition A/I dans l'ARN messager de la sousunité GluR-B du cerveau est distincte de l'enzyme qui catalyse la formation d'inosines dans les double-brins d'ARN dans ces mêmes cellules. Il est probable que d'autres enzymes d'édition coexistent, chacune spécifique d'un type d'ARN messager à éditer, voire d'une adénosine en un site déterminé de l'ARNm. Toutefois, la sélectivité du système d'édition pour- 
rait également dépendre de la présence de facteurs permettant de cibler l'enzyme aux sites d'édition. Ces facteurs pourraient être inductibles et n'apparaître dans la cellule qu'à certains moments de son cycle ou de son développement cellulaire. Quel que soit le mode de reconnaissance de la cible par le système d'édition de l'ARN, la conformation de l'acide nucléique au site d'édition semble jouer un rôle prépondérant. Une situation qui pourrait avoir des ressemblances avec le système de modification des nucléosides dans les autres types d'ARN. Près de 90 types de nucléosides modifiés différents ont été recensés dans les ARN, principalement dans les ARN de transfert [32]. Ces modifications vont de la simple addition d'un groupe méthyle à des modifications très complexes faisant intervenir plusieurs enzymes. Chacune de ces modifications est catalysée par des enzymes extrêmement spécifiques non seulement du type de nucléoside à modifier mais également de sa localisation au sein d'une architecture précise de l'ARN. C'est le cas, par exemple, des formations des inosines 34 et 37 dans l'ARNt-ala de levure qui sont catalysées par deux enzymes distinctes et qui nécessitent une structure tridimensionnelle de l'ARNt parfaitement définie. En revanche, l'enzyme nucléaire qui catalyse la désamination de plusieurs adénosines pour former des inosines dans des régions en double-brin d'ARN est clairement moins dépendante de l'architecture de l'ARN puisqu'elle est capable de modifier une série d'adénosines. Cette enzyme initialement découverte grâce à ses propriétés de "déroulase" d'ARN en double-brin est impliquée dans le processus d'hypermutation d'ARN viraux (les measles virus) lors de leur transcription et de leur réplication dans la cellule hôte. Enfin, une différence fondamentale et remarquable entre le système d'édition de l'ARNm de l'apolipoprotéine B dans l'intestin et celui des ARNm de récepteurs du glutamate dans le cerveau, à part le type de base qui sera désaminée (cytidine ou adénosine), concerne la stricte dépendance du système d'édition des GluR vis-à-vis d'éléments contenus dans la séquence et/ou la structure (archi-
Les enzymes d'édition ont la lourde responsabilité de modifier l'information génétique du gène au niveau de l'ARN. Quel est le degré de fiabilité des systèmes d'édition? Quels sont les points communs ou différences fondamentales entre les différents systèmes d'édition identifiés à ce jour ? De quels signaux cellulaires leurs activités dépendent-elles ? Combien d'enzymes et de facteurs sont-ils impliqués? De quelles manières leurs fonctions sont-elles programmées et génétiquement contrôlées? Quelle est l'origine évolutive de ce nouveau processus de régulation post-transcriptionnelle de l'expression génétique $\left(m / s n^{\circ} 10\right.$, vol. $\left.9, p .1116\right)$ ? Autant de questions fondamentales pour lesquelles nous espérons obtenir des réponses. Egalement, la recherche d'inhibiteurs sélectifs de l'activité enzymatique de cette famille d'enzymes d'édition (ARN-désaminases) devrait permettre d'envisager une nouvelle thérapie pour interférer sélectivement avec l'expression de certains ARN messagers et/ou la persistance de certains virus à ARN dans une cellule hôte

\section{Remerciements}

Outre l'aide financière du CNRS, les auteurs ont bénéficié de fonds de l'Association pour la recherche sur le cancer (ARC, période 1993 . 1996), la Ligue nationale contre le cancer (1993) et l'Association française contre les myopathies (AFM, période 1994 et 1995).

\section{Summary}

Edition and modification of RNA from eukaryotic cells and viruses by enzymatic deamination of adenosine to inosine

The presence of inosine in the anticodon of several transfer RNAs (tRNA) of eukaryotic cells has been known for a long time. Recent work has now demonstrated that inosine is present in other RNAs, namely in the coding region of messenger RNA for the glutamate receptor (GluR mRNA) of mammalian brain, in the non-coding RNA transcript (TAR domain) of immunodeficiency virus type HIV-1, and in the double-stranded regions of eukaryotic mRNA associated with antisense oligonucleotides (dsRNA). It is likely that inosine is also present in the primary replicative transcripts of certain viruses (measles virus). These inosine residues are produced by specific nuclear RNA deaminases. These newly discovered enzymes catalyze the hydrolytic deamination of selected adenosines during the complex process of RNA maturation (post-transcriptional events). In cytoplasmic mRNA and in viral RNA, inosine behaves like guanosine in subsequent transcription and translation processes, leading to alteration of the DNA coded genetic information (editing). In tRNA, inosine in the first anticodon position restricts the pairing with the third base in mRNA codons to $\mathrm{U}, \mathrm{C}$ and $\mathrm{A}$, while inosine (its methylated derivative; $\mathrm{ml} \mathrm{I}$ ) adjacent to the anticodon of certain eukaryotic tRNA possibly helps maintaining the correct reading frame of the mRNA during the translation pro cess. In double stranded RNA, inosine residues facilitate unwinding and consequently the degradation of the nucleic acid by endogeneous nucleases. An important question is how the different adenosine deaminases recognize their target nucleotides within RNA. The sequence and/or conformation (architecture) of the RNA around the modification-editing sites are important. It could also be that the site-specific adenosine deamination (A/I conversion) in GluR mRNA of mammalian brain depends on RNA recognition by proteins that specifically target the catalytic RNA adenosine deaminase to the editing site. This would be analogous to the sitespecific cytosine deamination $(\mathrm{C} / \mathrm{U}$ conversion) in the apolipoprotein $\mathrm{B}$ mRNA of mammalian intestine. 